\title{
Quantitative \& Qualitative Regulation of Peripheral Leukocyte Subsets plus Emotional Hormones by Floor Heating
}

\author{
Nobuo Yamaguchi1,2*, Amat Nurmuhammad ${ }^{3}$, Jameas Zhao', Xiufeng Jia4, Jiao Jian', \\ Rui Chen", Tsugiya Murayama ${ }^{5}$ \\ ${ }^{1}$ Ishikawa Natural Medicinal Products Research Center, Kanazawa, Japan \\ ${ }^{2}$ Department of Fundamental Research for Complementary and Alternative Medicine, \\ Kanazawa Medical University, Ishikawa, Japan \\ ${ }^{3}$ Uighur Medicine Department of Xinjiang Medical University, Urumqi City, China \\ ${ }^{4}$ Union Hospital, Tongji Medical College, Huazhong University of Science and Technology, \\ Wuhan, China \\ ${ }^{5}$ Deaprtment of Microbiology and Immunology, Faculty of Pharmaceutical Sciences, Hokuriku University, \\ Kanazawa, Japan \\ Email: *serumaya@kanazawa-med.ac.jp
}

Received 5 March 2014; revised 5 April 2014; accepted 12 April 2014

Copyright (C) 2014 by authors and Scientific Research Publishing Inc.

This work is licensed under the Creative Commons Attribution International License (CC BY). http://creativecommons.org/licenses/by/4.0/

(c) (i) Open Access

\section{Abstract}

A floor heating system is a traditionary famous in Asian countries, especially in North East of China and Korea. In this report, we intended to clarify the effect of floor hating system for accessing a peripheral leukocyte regulation in winter season by evidence-based manner more than VAS. We set up two different office rooms heat-controlled by floor heating and air-conditioned by ceiling electric heater. Both qualitative and quantitative approaches determine which are better therapeutic effective recipes for this trial. The elements were evaluated by the total number of peripheral leukocyte, granulocyte and lymphocyte ratio and lymphocyte subsets. For 5 days of working in each conditioned room, the volunteers were changed the room after one-week interval for cooling down. Floor heating system regulated total number of peripheral leukocyte. The mode of the action for the high number of the volunteer was down-regulated. On the contrary, in lower numbers it was up-regulated after the trial. The number of leukocyte subsets, granulocyte and lymphocyte were also regulated by dose dependent manner. Emotional hormone, adrenalin, cortisone and nor-adrenaline were down regulated by floor heating but dopamine was up-regulated by this heating system. The reversal results were obtained by the group who worked in the conditioned room by the system heating from ceiling.

\footnotetext{
${ }^{*}$ Corresponding author.
}

How to cite this paper: Yamaguchi, N., et al. (2014) Quantitative \& Qualitative Regulation of Peripheral Leukocyte Subsets plus Emotional Hormones by Floor Heating. Open Journal of Rheumatology and Autoimmune Diseases, 4, 97-105. 


\section{Keywords}

\section{Room Temp Control, Floor Heating, Leukocyte Subsets Ratio, Emotional Hormone}

\section{Introduction}

A choice of health menu in conjunction with each constitution is in a quandary due to the lack of information concerning these cross-interactions among general public and the lack of information among the health professionals resulting with a potentially significant health scale.

A vertebrate animal acquire two ontogenically and phylogenically defense systems and ontogenetically, innate and adaptive. Despite these defense systems overwhelming problems of possessing these dual systems, the innate and adoptive system does not seem to guard or even prevent the development of one internal threat to survival. However, every individual exposes to the risks of immunodeficiency status in daily life with both internal and externals [1]-[12]. The factors that influence the acquired immune activity are systemic metabolic disorders such as diabetes mellitus, malnutrition, extreme exhaustion, extensive stress, aging and medical side effects [1]-[12]. So we have to select an appropriate menu to regulate the immune function through the leukocyte storage.

In other words, no tentative scale evaluates the intense of each trial. We have reported the best tailored scale by different menus through the leukocyte regulation in number and function [13]. For this purpose, we tried to set up two different intense menus for the same volunteers by different modes of room heating, head cooling plus foot heating (HCFH) and head heating plus foot cooling (HHFC).

It is known that the immune system is closely related to the circadian rhythms, nervous and endocrine systems [14]. It seems reasonable that a heating system should also influence the immune system, but so far no objective studies have been made. In order to investigate the influence of room heating system on the immune system, we set up the different trials to the same volunteers at the different time with one-week cooling in mid winter in Japan, 2-30 February, 2009.

\section{Subjects and Methods}

\subsection{Subjects}

We selected 11 healthy volunteers (mean age, $43.8 \pm 11.2$ years, ranging $23-55$ years old in both sexualities) and informed consented according to The Ethics Committee of Kanazawa Medical University. The contents of sexuality were $45.3 \%$ of the lady and $54.7 \%$ for gentleman. They were the students of Medical University and the stuff for the school of medicine. The volunteers were divided in to two group and each group was started, either FHHC experimental group or control group. After 5 days later, the blood samples were prepared at the same hour of the first blood sampling (Figure 1).

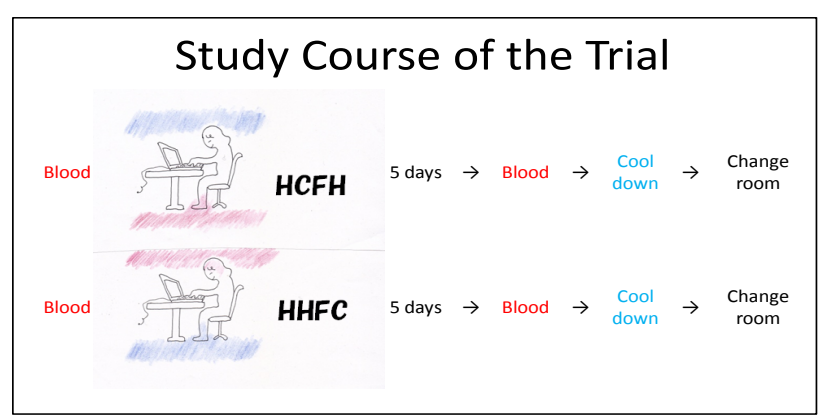

Figure 1. Experimental design of this report: The different air-conditioned rooms were set up and served for this trial. HCFH; indicating head cool and foot hot setting, HHFC; indicating head hot and foot cool setting, for this trial. In both room, room temperatures were adjusted $18^{\circ} \mathrm{C}$ at $150 \mathrm{~cm}$ from the floor. We sampled peripheral blood from the 11 volunteers before and after working in each heating system dilation at the same time zone of each day, with the consideration of circadian rhythm of leukocyte. 


\subsection{Adjusting Room Temperature $18^{\circ} \mathrm{C}$ by Floor Heating}

These subjects participated in this study after giving their informed consent. We conducted the study by setting the control group at the same period and same building. The room controlled by floor heating was $18^{\circ} \mathrm{C}$ at 150 $\mathrm{cm}$ from the floor. We sampled peripheral blood from the 14 volunteers before and after this study at the same time on each day, in consideration of circadian rhythm [15] [16] of leukocyte. The trial started at ten o'clock for about hours, consecutive for 5 day [17] [18]. Time interval of blood sampling between before and after the trial was approximately 120 hours. Measurements of the total leukocyte were assessed for differential leukocyte counts, and granulocyte and lymphocyte ratio in the peripheral blood.

We ordered to the laboratory of Ishikawa Prefecture Preventive Medicine Association for precise counts for the total and differential leukocyte counts in the peripheral blood from the subjects. The total and differential leukocyte counts were measured by the automated hematology analyzer XE-2100 (Sysmex, Inc., Kobe, Japan).

\subsection{Adjusting Room Temperature $18^{\circ} \mathrm{C}$ by Hot Air on the Ceiling}

Another group subjected in this study after giving their informed consent. We conducted the study by setting the control group at the same period and same building. The room controlled by hot air heating by electric device was $18^{\circ} \mathrm{C}$ at the height $150 \mathrm{~cm}$ from the floor.

After one-week cooling down for all volunteers, we set up again for the same study exchange the room for trial. We prepared peripheral blood from the same 11 volunteers before and after their trial, at the same hour on the day, in consideration of circadian rhythm [19] [20] of leukocyte.

\subsection{Assessment of Lymphocyte Subsets by FCM}

For the purpose of estimating CD positive cell, the whole blood was obtained from the subjects by blood collection tube containing an anticoagulant EDTA-2K. $100 \mu \mathrm{l}$ of whole blood were added in the antibody. After washing with PBS, the suspensions were mixed phycoerythrin (PE)-conjugated streptavidin (Beckman Coulter Inc. France) and fluorescence monoclonal antibody: peridinin chlorophyll protein-cyanin 5.5 (PerCP-Cy5.5)-conjugated CD2, fluorescein isothiocyanate (FITC)-conjugated CD4, FITC-conjugated CD8, FITC-conjugated CD16, FITC-conjugated CD19, FITC-conjugated CD57 (each Becton Dickinson Co. USA), allophycocyanin (APC)conjugated CD8, and APC-conjugated CD57 (each Beckman Coulter). The negative controls were added PE-conjugated streptavidin and the isotype control antibodies to the CD antibodies. After incubation for $30 \mathrm{mi}-$ nutes at $4^{\circ} \mathrm{C}$, these samples were hemolyzed using a 10-times dilution FACS Lysing Solution (Becton Dickinson). After washing with PBS, the cell suspensions were fixed using a 10-times dilution CellFIX (Becton Dickinson) and analyzed by flow cytometer FACS Caliber (Becton Dickinson) [21]-[23].

\subsection{Statistical Analysis}

The statistical comparisons between two groups (before and after trial) for the test of significant difference were performed by paired t-test and wilcoxon signed-ranks test. Further, the test of the correlation was performed a spearman's correlation coefficient by rank test. Data are expressed as means \pm standard error of mean (SE). A p value $<0.05$ was considered to be statistically significant. The Kendall tau Rank Correlation and the two-sided p-value $(\mathrm{H} 0$ : tau $=0)$. The ordinary scatter plot and the scatter plot between ranks of X \& Y is also shown [24].

\section{Results}

\subsection{Twenty-Four Hours Change of Leukocyte Counts after Working in the Room Heating by Floor}

Each volunteer was prepared their blood before start for trial and after informed consented to the experimental purpose by written Ethics of the Committee in Kanazawa Medical University. We tried to exhibit the effect of peripheral total leukocyte number by individual level of change and plot in the $\mathrm{x}$-axis as in each value before the exercise. As shown in Figure 2, the relative value (\%) was calculated before and after the exercise and plotted in the figure of the $\mathrm{x}$-axis according to the value before exercise. As a result of the trial, there found three groups, separated, up-regulated individuals and down-regulated one and was no change. The correlation of change was expressed as a linear function and significant reverse correlation, -0.6893 indicating ideal value of correlative 

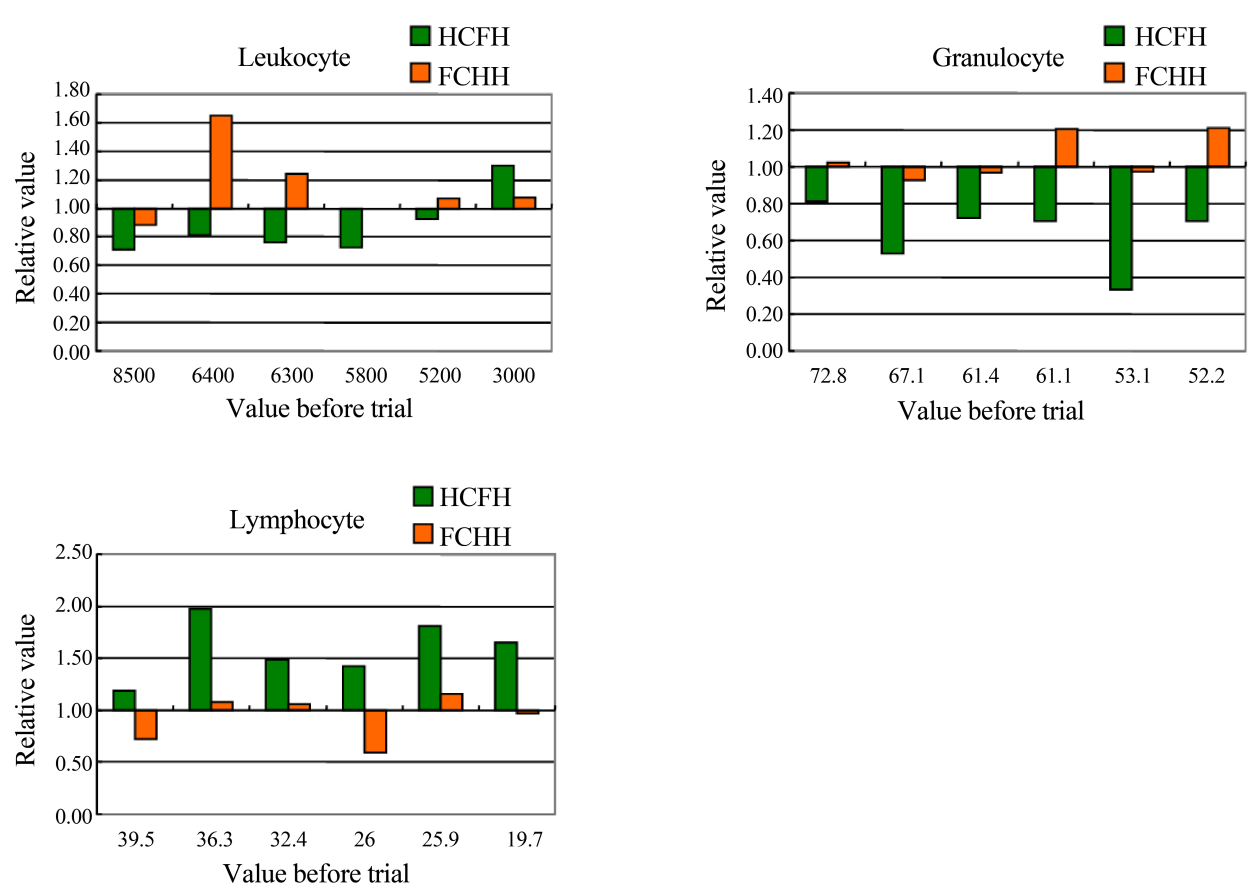

Figure 2. We tried to express the effect of peripheral total leukocyte number by individual level. The results were indicated in the $\mathrm{x}$-axis as with each value before the trial. The relative value (\%) of post trial was calculated with before and after and indicated in the y-axis. Total leukocytes, leukocyte subset, granulocyte and lymphocyte were also traced in the figures.

index -0.5 (Figure 3). The data obtained from 4 mets exercise was brought ideal regulation. However, 8 mets could not bring such a effect significantly. About the leukocyte subset, the ideal regulation of lymphocyte and monocyte were found by floor heating room.

\subsection{Twenty-Four Hours Change of Leukocyte Counts after Heating by Hot Air from Overhead}

None of volunteer was dropped out with any serious problem. In trial, we set up room temperature also $18^{\circ} \mathrm{C}$ at the $150 \mathrm{~cm}$ in high from floor, we tried to express the effect of peripheral total leukocyte number by individual level of change and plot in the $x$-axis as in each value before the exercise as is in 3.1 (Figure 3). As shown in lower panel in Figure 3, the correlation was exhibited on a linear function but good correlation was retreated from the results The data obtained from 8 mets exercise was lesser regulatory effect than that compared by 4 mets of exercise. About the leukocyte subset, the regulation by lymphocytes was more remarkable. However, only the monocyte exhibited significant change by both.

\subsection{Leukocyte Subsets Regulation by Floor Heating}

After one-week working in the conditioned room as HCFH or HHFC, we set up the different mode of trial at the same course and by the same volunteers. None of volunteer was dropped out with any serious problem. In this time, we set up HCFH system, asking to work about for 5 days. We selected four hormones and accessed the effect of HCFH or HHFC conditioned room. After working about regular desk working in the HCFH conditioned room, each volunteer was down-regulated the adrenaline, cortisone and nor-adrenalin. However, Dopamine level was up-regulated for all the individuals tested. On the other hand, HHFC system showed reversed effect for all the hormones in this text.

\subsection{Twenty-Four Hours Changes and Exhibition by the Serum Hormonal Level before the Trial}

After one-week working in the conditioned room as HCFH or HHFC, we set up the different mode of trial at 

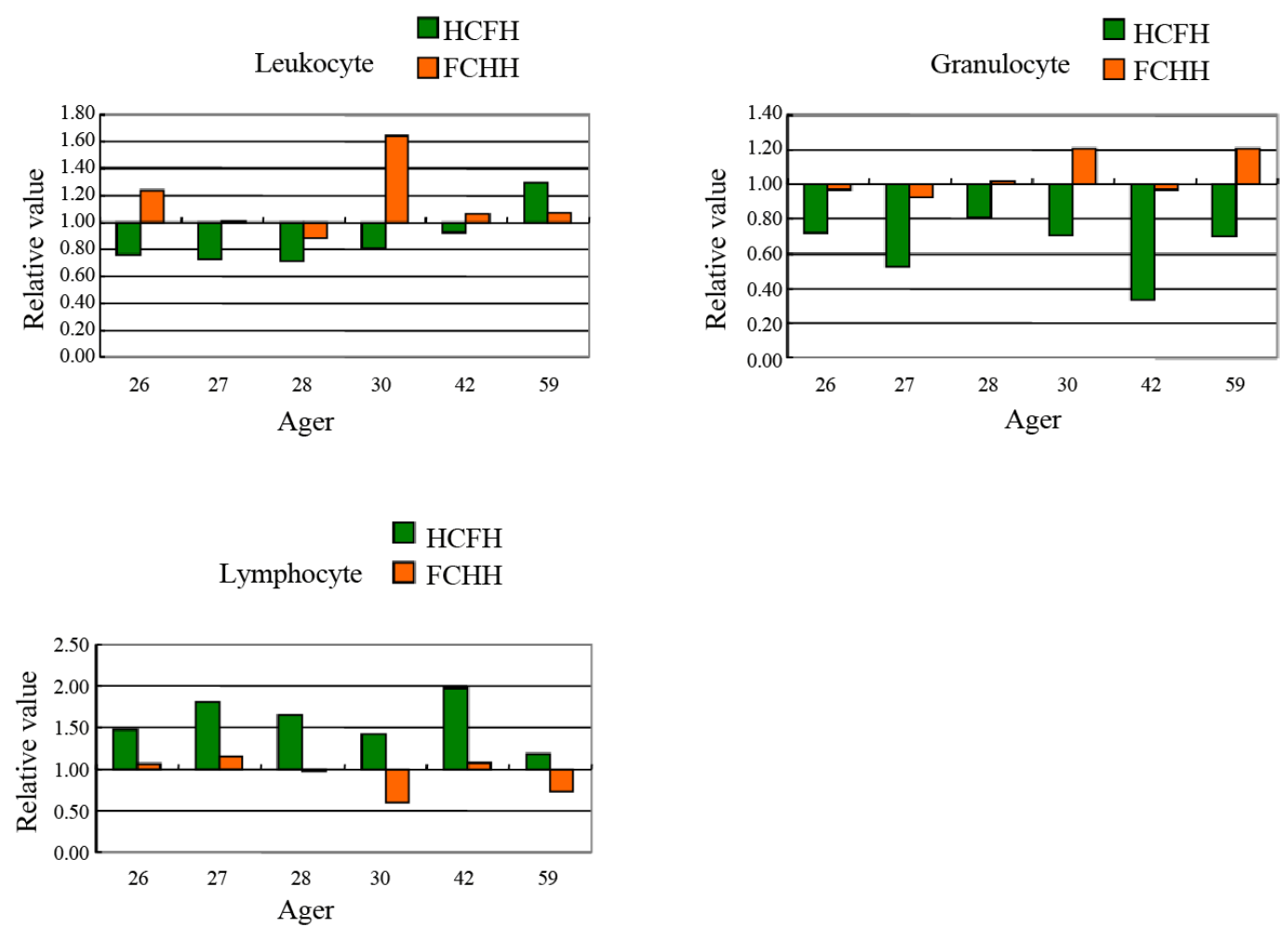

Figure 3. We tried to express the effect of peripheral total leukocyte number by individual level of change and plot in the $\mathrm{x}$-axis as in each value according to the age. The relative value (\%) of post trial was calculated with before and after and indicated in the y-axis. Leukocyte subset, granulocyte and lymphocyte were also showed in the figures.

the same course and by the same volunteers. None of volunteer was dropped out with any serious problem. In this time, we set up HCFH system, asking to work about for 5 days. We selected four hormones and accessed the effect of HCFH or HHFC conditioned room. After working about regular desk working in the HCFH conditioned room, each volunteer was down-regulated the adrenaline, cortisone and nor-adrenalin. However, Dopamine level was up-regulated for all the individuals tested. On the other hand, HHFC system showed reversed effect for all the hormones in this text (Figure 4, Figure 5).

\section{Discussion}

Our results showed that within 24 hours after light exercise, the white blood cells in peripheral blood had regulated significantly, not only in leukocyte subset but also lymphocyte subset. The results showed that these subsets could reflect the number and function of immuno-competent cells [13] [25]-[30]. For example, in an individual with a low granulocyte number, the number increased after treatment, while it decreased in another individual with a higher cell number. Our results led us to believe that leukocyte subsets could be an interesting indicator for the evaluation of alternative therapies. Many systems are in place to evaluate Western therapies that aim at healing the symptoms of an illness. We hope that our work will attract more attention to the mechanisms of which each CAM menu regulates the human immune system. Abo reported that according to the lymphocyte subset content, lymphocyte rich type showed over $40 \%$ on the other hand granulocyte rich type show over $60 \%$ of granulocyte. Each type exhibited different character even in the same age, sexuality and different age. Within the same age and the sexuality, even in gentleman can sorts out as G-rich type (granulocyte 60\%), and L-rich type (lymphocyte $40 \%$ ). On the other hand, as a stand point of sexuality difference, the lady belongs to L-rich type but the gentleman belongs to G-rich type. According to the age-related change, G-rich type of young man has changed into L-rich type according to getting older [19] [31]. We have been trying to regulate the immune responsiveness through much mature by fragile daily condition from circumstance stress and so on. The main menu were, acupuncture, hot-spring hydrotherapy, light exercise etc. In this article, we would like to show the 

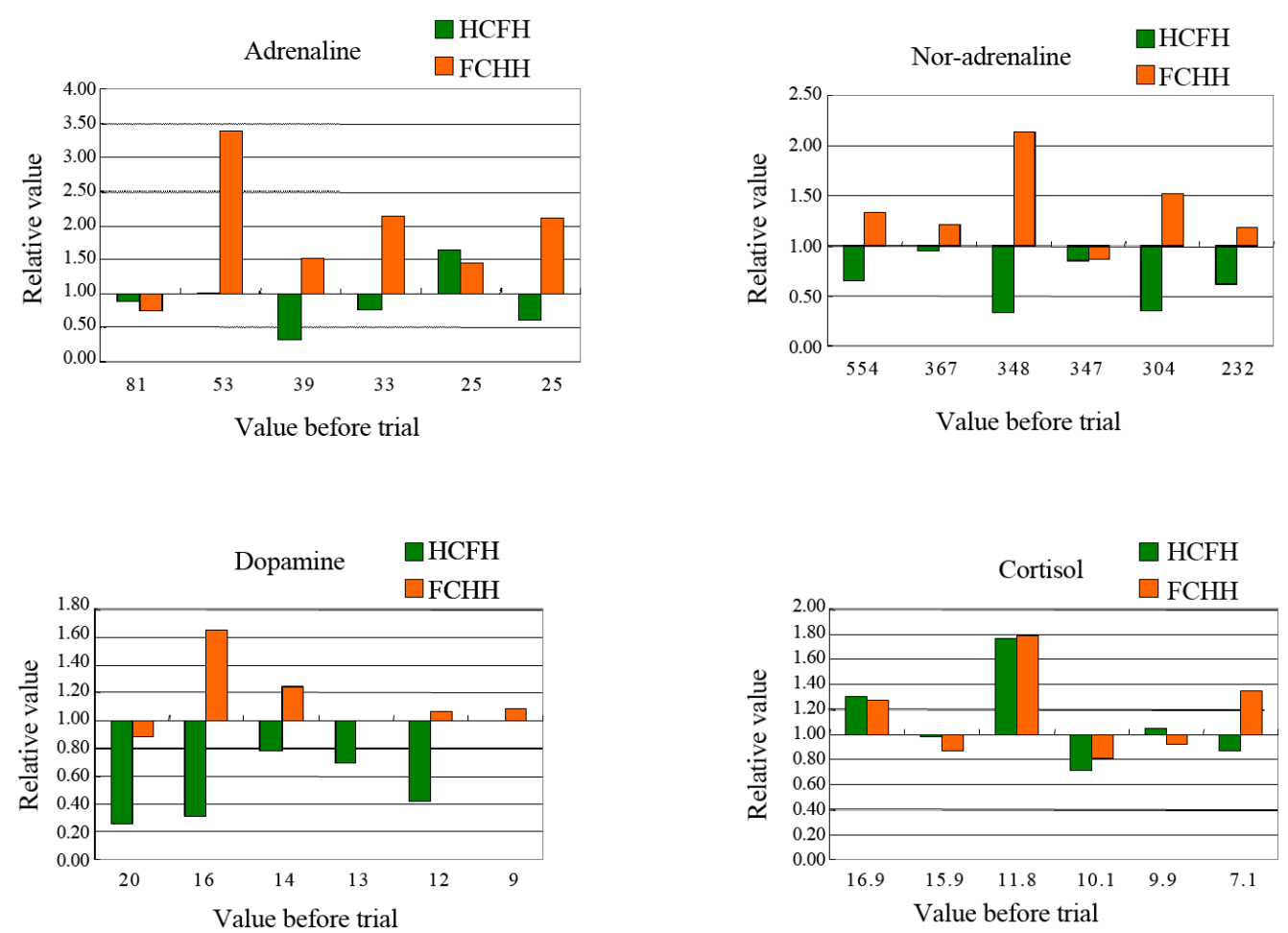

Figure 4. We tried to express the effect of HCFH \& FCHH system on emotional hormones by individual level of change and plot in the $\mathrm{x}$-axis as in each degree of hormonal level before the trial. The relative value $(\%)$ of post trial was calculated with relative ratio before and after and plotted in the y-axis. Adrenalin, nor-adrenaline, dopamine and cortisone were exhibited in the figures.
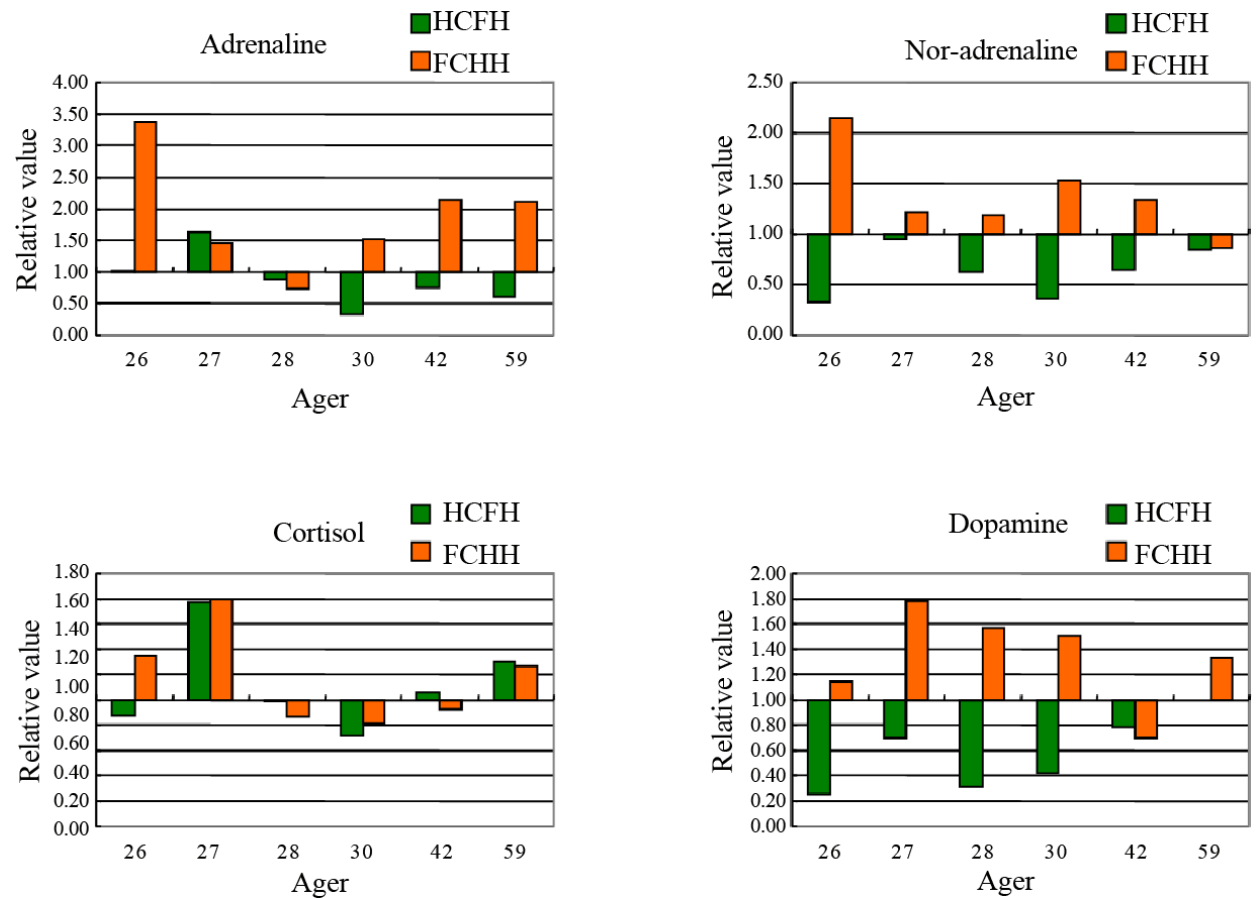

Figure 5. We tried to express the effect of HCFH \& FCHH system on emotional hormones by individual level of change and plot in the $\mathrm{x}$-axis as in each ager before the trial. The relative value $(\%)$ of post trial was calculated with relative ratio before and after and plotted in the y-axis. Adrenalin, noradrenaline, dopamine and cortisone were exhibited in the figures. 
regulatory mechanism of the light exercise walking as a tailored scale. The circumstance, except for cases of contraindication, has been medically useful approved to be effective in many stress-related disorders and the improvement of dysfunction of the biological rhythm disturbance as well as chronic disease. The mechanism of effects has been reported in many studies, but many things are still unclear.

In order to assess correctly to the changes after the menu, it is important to conscious of circadian rhythm. Abo also reported that it was possible to sort the constitution, granulocyte-rich individual and lymphocyte-rich one with the peripheral leukocyte [20] [32]-[35].

Each population of subset is depends on a circadian rhythm. Within a same individual, granulocyte increase in the daytime, on the other hand, lymphocyte increased in the night time in a cycle $24 \mathrm{hrs}$. So we have to compare the effect of each menu for the peripheral leukocyte on the same time before and after the menu.

With our report simple comparison of grouped value did not exhibit the valuable change in each individual. So this style of presentation was suggestive to the patient for immunodeficiency such as in DM.

It was reported that the leukocyte subset, granulocyte and lymphocyte regulated by various factors. One major point is that they are regulated by autonomous nervous system [36], resulting in circadian rhythm [15] [16]. Therefore, in order to access the effect within a short time, it is necessary to consider this factor to adjust the time to collect the sample. For example, efficacy and impact of walking exercise has been widely recognized. However, the majority of walkers did not have a scientific background to know the best exercise menu for the one' QOL; quality of life. The purpose of this study was to demonstrate the best menu of walking that regulates the peripheral white blood cells in number and function as a marker of QOL expression.

However, almost all the judgments of efficacy are VAS (visual analog scale). Moreover, simple processing by grouped value and make mean fadeout the precise regulation according to each constitution. Therefore, we hope our tailored scale can be suggested to assess every CAM therapies in the world for competition.

\section{Conclusions}

We have measured the number of leukocyte subsets, granulocyte and lymphocyte ratio after different modes of room heating systems. The conclusions were as following.

1) The quantitative regulation of total leukocyte number could be assessed by the down-regulated, namely tailored scale for each constitution.

2) HCFH proved to regulate the total number of leukocyte subsets, granulocyte and lymphocyte.

3) $\mathrm{HCFH}$ proved down-regulated for granulocyte number, but up-regulated for lymphocyte.

4) HCFH down regulated the adrenalin level, so as to cortisone and nor-adrenaline.

5) HHFC showed a reverse effect for regulating the number of leukocyte, subset.

6) HHFC showed a reverse effect for regulating the serum emotional hormone compared by HCFH.

\section{Conflict of Interests}

No conflict of interest hits in this trial.

\section{References}

[1] Kurashige, G.S., Yoshida, T. and Mitsuhashi, S. (1980) Immune Response in Sarcoma10-Bearing Mice. Annual Report of Gunnma University, 1, 36-44.

[2] Yamaguchi, N., Shimizu, S. and Saito, T. (1983) The Effect of Maternal Antigenic Stimulation upon the Active Immune Responsiveness of Their Offspring. Immunology, 50, 229-238.

[3] Kishida, Miyazaku, S., Take, H., Fujimoto, T., Shi, H., Sasaki, K. and Goya, N. (1978) Granial Irradiation and Lymphocyte Subpopulation in Acute Lymphatic Leukemia. Journal of Pediatrics, 92, 785-786. http://dx.doi.org/10.1016/S0022-3476(78)80155-3

[4] Yamaguchi, N., Takei, T., Chen, R., Wushuer, P. and Wu, W.H. (2013) Maternal Bias of Immunity to Her Offspring: Possibility of an Autoimmunity Twist out from Maternal Immunity to Her Young. Open Journal of Rheumatology and Autoimmune Diseases, 3, 40-55. http://dx.doi.org/10.4236/ojra.2013.31008

[5] Murgita, R.A. and Tomasi, Jr., T.B. (1975) Suppression of the Immune Response by Alpha-Fetoprotein. The Journal of Experimental Medicine, 141, 269-286. http://dx.doi.org/10.1084/jem.141.2.269

[6] Paul, G., Margaret, S., Liew, Y.F. and Allan, M.M. (1995) CD4+ but Not CD8+ T Cells Are Required for the Induction of Oral Tolerance. International Immunology, 7, 501-504. http://dx.doi.org/10.1093/intimm/7.3.501 
[7] Koshimo, H., Miyazawa, H.Y., Shimizu, Y. and Yamaguchi, N. (1989) Maternal Antigenic Stimulation Actively Produces Suppressor Activity in Offspring. Developmental \& Comparative Immunology, 13, 79-85. http://dx.doi.org/10.1016/0145-305X(89)90020-7

[8] Zoeller, M. (1988) Tolerization during Pregnancy: Impact on the Development of Antigen-Specific Help and Suppression. European Journal of Immunology, 18, 1937-1943. http://dx.doi.org/10.1002/eji.1830181211

[9] Auerback, R. and Clark, S. (1975) Immunological Tolerance: Transmission from Mother to Offspring. Science, 189, 811-813. http://dx.doi.org/10.1126/science.1162355

[10] Shinka, S., Dohi, Y., Komatsu, T., Natarajan, R. and Amano, T. (1974) Immunological Unresponsiveness in Mice. I. Immunological Unresponsiveness Induced in Embryonic Mice by Maternofetal Transfer of Human-Globulin. Biken Journal, 17, 59-72.

[11] Aase, J.M., Noren, G.R., Reddy, D.V. and Geme, Jr., J.W. (1972) Mumps-Virus Infection in Pregnant Women and the Immunologic Response of Their Offspring. The New England Journal of Medicine, 286, 1379-1382. http://dx.doi.org/10.1056/NEJM197206292862603

[12] Cramer, D.V., Kunz, H.W. and Gill, III, T.J. (1974) Immunologic Sensitization Prior to Birth. American Journal of Obstetrics \& Gynecology, 120, 431-439.

[13] Yamaguchi, N., Chen, R., Okamoto, K., Takei, T., Tsubokawa, M., Sakamoto, D., Jia, X., Wan, W. and Murayama, T. (2013) Quantitative Regulation of Peripheral Leukocyte by Light Exercise and Tailored Scale for Assessment. Open Journal of Immunology, 3, 175-183.

[14] Yamaguchi, N., Shimizu, S. and Izumi, H. (2004) Hydrotherapy Can Modulate Peripheral Leukocytes: An Approach to Alternative Medicine In: Cooper, E.L. and Yamaguchi, N., Eds., Complementary and Alternative Approaches to Biomedicine, Kluwer Academic/Plenum Publishers, New York, 239-251.

[15] Ignarro, L.J. and Colombo, C. (1973) Enzyme Release from Polymorphonuclear Leukocyte Lysosomes: Regulation by Autonomic Drugs and Cyclic Nucleotides. Science, 180, 1181-1183. http://dx.doi.org/10.1126/science.180.4091.1181

[16] Abo, T., Kawate, T., Itoh, K. and Kumagai, K. (1981) Studies on the Bioperiodicity of the Immune Response. 1. Circadian Rhythms of Human T, B and K Cell Traffic in the Peripheral Blood. Journal of Immunology, 126, 1360-1363.

[17] Suzuki, S., Toyabe, S., Moroda, T., Tada, T., Tsukahara, A., Iiai, T., et al. (1997) Circadian Rhythm of Leukocytes and Lymphocytes Subsets and Its Possible Correlation with the Function of the Autonomic Nervous System. Clinical Experimental Immunology, 110, 500-508. http://dx.doi.org/10.1046/j.1365-2249.1997.4411460.x

[18] Guenette, J.A., Dominelli, P.B., Reeve, S.S., Durkin, C.M., Eves, N.D. and Sheela, A.W. (2010) Effect of Thoracic Gas Compression and Bronchodilation on the Assessment of Expiratory Flow Limitation during Exercise in Healthy Humans. Respiratory Physiology \& Neurobiology, 170, 279-286. http://dx.doi.org/10.1016/j.resp.2010.01.017

[19] Huang, Y.H., Haegerstrand, A. and Frostegard, J. (1996) Effect of in Vitro hyperthermia on Proliferative Responses and Lymphocyte Activity. Clinical Experimental Immunology, 103, 61-66. http://dx.doi.org/10.1046/j.1365-2249.1996.00932.x

[20] Abo, T. and Kumagai, T. (1978) Studies of Surface Immunoglobulins on Human B Lymphocytes. III. Physiological Variations of Sig+ Cells in Peripheral Blood. Clinical Experimental Immunology, 33, 441-452.

[21] Guenette, J.A., Querido, J.S., Eves, N.D., Chua, R. and Sheel, A.W. (2009) Sex Differences in the Resistive and Elastic Work of Breathing during Exercise in Endurance-Trained Athletes American Journal of Physiology: Regulatory, Integrative and Comparative Physiology, 297, 166-175. http://dx.doi.org/10.1152/ajpregu.00078.2009

[22] Komine, H., Sugawara, J., Hayashi, K., Yoshizawa, M. and Yokoi, T. (2009) Regular Endurance Exercise in Young Men Increases Arterial Baroreflex Sensitivity through Neural Alteration of Baroreflex Arc. Journal of Applied Physiology, 106, 1499-1505. http://dx.doi.org/10.1152/japplphysiol.91447.2008

[23] Dulis, B.H. and Wilson, I.B. (1980) The $\beta$-Adrenergic Receptor of Live Human Polymorphonuclear Leukocytes. Journal of Biological Chemistry, 255, 1043-1048.

[24] Ostberg, J.R., Patel, R. and Repasky, E.A. (2000) Regulation of Immune Activity by Mild (Fever-Range) Whole Body Hyperthermia: Effect on Epidermal Langerhans Cells. Cell Stress Chaperones, 5, 458-461.

[25] Wang, X.-X., Kitada, Y., Kenichiro, M.K., Ohkawa, S., Sugiyama, T., Kohno, H., Shimizu, S., Lai, J.-E., Matsuno, H. and Yamaguchi, N., (1999) Variation of Cell Populations Taking Charge of Immunity in Human Peripheral Blood Following Hot Spring Hydrotherapy Quantitative Discussion. The Journal of Japanese Association of Physical Medicine, Balneology and Climatology, 62, 129-134.

[26] Matsuno, H., Wang, X.-X., Wan, W., Matsui, K., Ohkawa, S., Sugiyama, T., Kohno, H., Shimizu, S., Lai, J.E. and Yamaguchi, N. (1999) Variation of Cell Populations Taking Charge of Immunity in Human Peripheral Blood Following Hot Spring Hydrotherapy Qualitative Discussion. The Journal of Japanese Association of Physical Medicine, Balneology and Climatology, 62, 135-140. 
[27] Yamaguchi, N., Hashimoto, H., Arai, M., Takada, S., Kawada, N., Taru, A., Li, A.L., Izumi, H. and Sugiyama, K. (2002) Effect of Acupuncture on Leukocyte and Lymphocyte Subpopulation in Human Peripheral Blood-Quantitative Discussion. The Journal of Japanese Association of Physical Medicine, Balneology and Climatology, 65, 199-206.

[28] Wan, W., Li, A.L., Izumi, H., Kawada, N., Arai, M., Takada, A., Taru, A., Hashimoto, H. and Yamaguchi, N. (2002) Effect of Acupuncture on Leukocyte and Lymphocyte Subpopulation in Human Peripheral Blood. Qualitative Discussion. The Journal of Japanese Association of Physical Medicine, Balneology and Climatology, 65, 207-211.

[29] Kitada, Y., Wan, W., Matsui, K., Shimizu, S., Yamaguchi, N., et al. (2000) Regulation of Peripheral White Blood Cells in Numbers and Functions through Hot-Spring Bathing during a Short Term-Studies in Control Experiments. Journal of Japanese Society Balneology Climatology Physiological Medicine, 63, 151-164.

[30] Yamaguchi, N., Takahashi, T., Sugita, T., Uchikawa, K., Sakaihara, S., Kanda, T., Arai, M. and Kawakita, K. (2007) Acupuncture Regulates Leukocyte Subpopulations in Human Peripheral Blood. Evidence-Based Complementary and Alternative Medicine, 4, 447-453.

[31] Valz, P.D. and Thompson, M.E. (1994) Exact Inference for Kendall's S and Spearman's Rho. Journal of Computational and Graphical Statistics, 3, 459-472. http://dx.doi.org/10.2307/1390906

[32] Mats, H., Orion, E. and Wolf, R. (2003) Balneotherapy in Dermatology. Dermatological Therapy, 16, 132-140. http://dx.doi.org/10.1046/j.1529-8019.2003.01622.x

[33] Sanders, V.M., Baker, R.A., Ramer-Quinn, D.S., Kasprowicz, D.J., Fuchs B.A. and Street, N.E. (1997) Differential Expression of the $\beta_{2}$-Adrenaergic Receptor by Th1 and Th2 Clones. Journal of Immunology, 158, 4200-4210.

[34] Maisel, A.S., Harris, T., Rearden, C.A. and Michel, M.C. (1990) Beta-Adrenergic Receptors in Lymphocyte Subsets after Exercise. Alterations in Normal Individuals and Patients with Congestive Heart Failure. Circulation, 82, 20032010. http://dx.doi.org/10.1161/01.CIR.82.6.2003

[35] Landmann, R.M.A., Müller, F.B., Perini, C., Wesp, M., Erne, P. and Bühler, F.R. (1984) Changes of Immunoregulatory Cells Induced by Psychological and Physical Stress: Relationship to Plasma Catecholamines. Clinical Experimental Immunology, 58, 127-135.

[36] Elenkov, I.J. and Crousos, G.P. (1999) Stress Hormones, Th1/Th2 Patterns, Pro/Anti-Inflammatory Cytokines and Susceptibility to Disease. Trends in Endocrinology \& Metabolism, 10, 359-368.

\section{Abbreviations}

CAM: Complementary and alternative medicine, beside the western medicine, there are many traditional medicine and/or health promoting menu all over the world.

CD: Cluster of differentiation. Each lymphocyte has name that expressed CD number, for example CD2, CD4, etc.

DM: Diabetes mellitus.

Emotional Hormone: Adrenaline, Dopamine and Cortisone were selected as emotional hormones for this trial.

FCM: Flow cytometry.

G-rich type: The individual that exhibit over $60 \%$ of granulocyte in peripheral blood, finding many in young gentleman.

HCFH: Head cooling and foot heating system.

FCHH: Foot cooling and head heating system.

L-rich type: The individual that exhibit over $40 \%$ of lymphocyte in peripheral blood, finding lot in ladies and senile.

QOL: Quality of life.

VAS: Visual analog scale. 